\title{
Designing soft/hard double network hydrogel microsphere/ UHMWPE composites to promote water lubrication performance
}

\author{
Chaobao WANG ${ }^{1,2}$, Xiuqin BAI ${ }^{1,2, *}$, Conglin DONG ${ }^{1,2}$, Zhiwei GUO $^{1,2}$, Chengqing YUAN $^{1,2, *}$, Anne NEVILLE ${ }^{1,3}$ \\ ${ }^{I}$ School of Energy and Power Engineering, Wuhan University of Technology, Wuhan 430063, China \\ ${ }^{2}$ Key Laboratory of Marine Power Engineering \& Technology (Ministry of Transport), Wuhan University of Technology, Wuhan \\ 430063, China \\ ${ }^{3}$ Institute of Functional Surfaces, School of Mechanical Engineering, University of Leeds, Leeds LS2 9JT, United Kingdom \\ Received: 17 February 2020 / Revised: 23 April 2020 / Accepted: 17 May 2020 \\ (C) The author(s) 2020.
}

\begin{abstract}
Several soft tissues residing in the living body have excellent hydration lubrication properties and can provide effective protection during relative motion. In order to apply this advantage of soft matters in practical applications and try to avoid its disadvantage, such as swelling and weakening in water, a design strategy of a soft/hard double network (DN) hydrogel microsphere modified ultrahigh molecular weight polyethylene (UHMWPE) composite is proposed in this study. A series of microspheres of urea-formaldehyde (UF), polyacrylamide (PAAm) hydrogel, UF/PAAm double network, and their composites were prepared. The mechanical properties, swelling, wettability, friction properties, and the lubrication mechanisms of the composites were investigated. The results show that DN microspheres can have an excellent stability and provide hydration lubrication. The performance of $75 \mathrm{DN}-1$ composite was superior to others. This finding will provide a novel strategy for the development of water-lubricated materials and have wide application in engineering fields.
\end{abstract}

Keywords: double network; microsphere; composite; friction properties; hydration lubrication

\section{Introduction}

When one surface moves over another, friction resistance will be generated to oppose the movement, which induces a huge waste of resources and energy in mechanical systems [1,2]. Using oily substances as a lubricant to reduce friction has always been a common approach [3, 4]. However, environmental pollution becomes more and more serious with the wide use of conventional oil lubricants, attention has gradually turned to using water as a natural lubricant, which is renewable, abundant, non-polluting, and can be conveniently stored and transported [5-8].
Water-lubricated bearings have been widespread used in ship power systems, which use water as a lubricant. The use of water-lubricated bearings can effectively avoid the leak of oil lubricants caused by the seal failure of oil-lubricated bearings, which has significance for the environmental protection and saving resources $[9,10]$. However, the viscosity of water is much less than that of oil, and also the pressure-viscosity coefficient poses a problem to obtain stable lubrication condition [11]. These shortages can cause low bearing capacity, severe wear, abnormal vibration, and noise to occur, which seriously reduce overall performance of a waterlubricated bearing and restrict its application.

* Corresponding authors: Xiuqin BAI, E-mail: xqbai@whut.edu.cn; Chengqing YUAN, E-mail: ycq@whut.edu.cn 
Designing innovative materials that can provide stable water-lubricated conditions is a continuing challenge.

The hydration lubrication of soft matters in living body provides a well-improved solution to the water-lubricated conditions and significantly protects the running organs of body. The charged polymer chains of soft matters can absorb surrounding water molecules to form hydration layers around them, which have truly remarkable lubrication in aqueous environments [12]. As one typical "soft-andwet" material, hydrogels that combine soft matter and hydration lubrication have been synthesized as one of the most important natural lubricator replacement materials due to its ultrahigh water lubrication capacity. It provides a new approach for developing water-lubricated bearing materials. Our previous work had shown that the hydration lubrication of polyacrylamide (PAAm) fragments could obviously reduce the sliding-friction in the PAAm/high density polyethylene (HDPE) composites under water-lubricated condition [13]. However, the natural flaws of PAAm particles, such as the swelling behaviours, also brought some surface defects and limited the further promotion of bearing capacity and lubrication.

The poor dimensional stability and mechanical property of hydrogels in water have been the largest obstacle to their applications [14]. To solve the problems, some scientists have created several novel methods to improve the performance of hydrogel, such as embedding soft hydrogel in a hard substrate [15] or designing double-network (DN) structures [16]. DN hydrogel is a kind of interpenetrating network gels consisting of a hard network and a soft network, wherein the hard network serves as main size keeping and bearing structure while the soft network maintains hydration lubrication. Therefore, DN hydrogel shows better stability and lubrication and possesses a great advantage in engineering fields.

Being a well-known engineering thermoplastics, ultrahigh molecular weight polyethylene (UHMWPE) has the advantages of low friction coefficient, superior wear resistance, good biocompatibility, high chemical stability, and good mechanical properties
$[17,18]$. Because of the prominent wear resistance, UHMWPE has been widely studied and applied in biotribology fields [19-21], and also shows the great practical potency in water-lubricated bearings [22]. However, the limitations caused by the low viscosity of water still exist and result in the degradation of the lubricating performance of UHMWPE. Filling modification is an effective and convenient way to modify the performance of UHMWPE due to its good processability [23-25]. As such, filling some hydrophilic components should be a viable solution to improve the lubricating performance of UHMWPE.

As described above, in order to develop a novel hydration lubrication composites with better lubricating capacity and performance stability, a series of new DN hydrogel microspheres/UHMWPE composites are prepared in the current work. The soaking surface morphology, swelling behaviour, wettability, and friction properties are reported, and the lubrication mechanism is also discussed. The findings can provide a composite strategy to transfer biological hydration lubrication to engineering fields.

\section{Material and methods}

\subsection{Raw materials}

The acrylamide, N,N'-Methylenebis (acrylamide) were obtained from Shanghai Macklin Biochemical Co., Ltd. The ammonium persulfate, xylene, ammonium chloride, triethanolamine, urea, and formaldehyde (37\% aqueous solution) were provided by Sinopharm Chemical Reagent Co., Ltd. Span 80 was supplied by Shanghai Aladdin Bio-Chem Technology Co., Ltd. The ultrahigh molecular weight polyethylene (UHMWPE, molecular weight 1.7 million) was purchased from Shanghai Research Institute of Chemical Industry.

\subsection{Preparation of microspheres}

Urea-formaldehyde (UF) resin was a thermosetting resin that was condensed by urea and formaldehyde. The curing process of UF resin included two steps, namely, methylolation reaction and post-curing. In the methylolation reaction, urea was mixed with formaldehyde ( $37 \%$ aqueous solution) by stirring 
in a reaction kettle, the U/F mole ratio was 2.0. After all urea was dissolved, the solution $\mathrm{pH}$ was adjusted to 8 with triethanolamine (TEA). The reaction solution was heated to $80{ }^{\circ} \mathrm{C}$ for $60 \mathrm{~min}$ to prepare the so-called methyloureas, then it was cooled to room temperature of $23{ }^{\circ} \mathrm{C}$. Finally, the right amount of ammonium chloride was dissolved in the reaction solution to prepare a methyloureas solution with $1 \mathrm{wt} \%$ ammonium chloride concentration.

Furthermore, different microspheres were prepared by emulsion polymerization. The acrylamide, N, $\mathrm{N}^{\prime}$-Methylenebis (acrylamide), and ammonium persulfate were dissolved in distilled water by the mole proportion of 100:1:0.5, and then mixed with methyloureas solution in proportions varying from 0 to $100 \%$. The mixed solution was dispersed in the mixed solvent of xylene and liquid paraffin containing span 80 as an emulsifier to form a stable W/O emulsion. The emulsion was purged with nitrogen gas for $1 \mathrm{~h}$ to completely exclude dissolved oxygen and then heated in the thermostat water bath at $75{ }^{\circ} \mathrm{C}$ to react. The cross-linking reactions proceeded for $4 \mathrm{~h}$ followed by post-processing for $8 \mathrm{~h}$ at $50{ }^{\circ} \mathrm{C}$. After the reaction, the emulsion was centrifuged. The precipitating microspheres were washed with distilled water and ethanol, and then dried under vacuum at room temperature. To better understand the different behaviors of UF hard network and PAAm soft network in water lubrication, UF microsphere, PAAm hydrogel microsphere, and three DN hydrogel microspheres with $25 \mathrm{wt} \%, 50 \mathrm{wt} \%$, and $75 \mathrm{wt} \%$ PAAm content were synthesized in this stage. The three DN hydrogel microspheres are denoted as $25 \mathrm{DN}, 50$ $\mathrm{DN}$, and $75 \mathrm{DN}$, respectively, in the rest of this paper.

\subsection{Preparation of composites and test samples}

A series of composites using different microspheres as the lubricated fillers were prepared. By considering the mechanical strength, water lubrication capacity, and cost comprehensively, the mass fractions of microspheres were set as follows: $1 \mathrm{wt} \%, 3 \mathrm{wt} \%$, and $5 \mathrm{wt} \%$, and were respectively denoted as " 1 ", " -3 ", and " -5 " that were displayed as a suffix. Before processing, the UHMWPE and microspheres were dried in the heating and drying oven at $80{ }^{\circ} \mathrm{C}$ for $12 \mathrm{~h}$ and were mixed for $60 \mathrm{~s}$ in a high-velocity mixer at 3,000 r/min. The composites were prepared by an internal mixer (QE-70B, Wuhan Qien Science and Technology Co., Ltd., China). The heating temperature of the mixing chamber was set to $200{ }^{\circ} \mathrm{C}$, and the rotor speed was $80 \mathrm{r} / \mathrm{min}$. The test samples were fabricated by different composites after dried at $80{ }^{\circ} \mathrm{C}$ for $4 \mathrm{~h}$ by an injection-molding machine (M1200S, Wuhan Qien Science and Technology Co., Ltd., China).

\subsection{Surface and morphology}

The surface morphology of the microsphere and the fracture morphology of polymer samples were examined by using a scanning electron microscopy (VEGA3, Tescan China, Ltd., China). To facilitate examination, all test samples were vacuum-coated with gold before testing. The swelling behavior of microspheres was observed using a 3D digital microscope (VHX-2000, Keyence Ltd., Japan). The worn surfaces were imaged by a laser scanning confocal microscope (VK-X2000, Keyence Ltd., Japan).

\subsection{Mechanical properties}

The mechanical properties were important parameters that determine the range of application and service lifespan of materials. The tensile strength, bending strength, ball indentation hardness, and Young's modulus of polymer were tested. The tensile strength, bending strength, and Young's modulus of material were tested in accordance with Chinese National Standard GB/T 1040.2-2006 by using a universal material testing machine (CMT6104, MTS Systems Ltd., China). The motion velocities during the tensile strength and bending strength tests were 20 and $2 \mathrm{~mm} / \mathrm{min}$, respectively. The ball indentation hardness of the material was tested according to Chinese National Standard GB/T 3398-2008 by using a ball indentation hardness tester (QYS-96B, Changchun Intelligent Instrument Equipment Ltd., China). All soaking strengths of polymer materials were obtained by measuring the specimens after soaking for seven days. 


\subsection{Wetting of composites}

The contact angle was an elleschic parameter, which was used to show the wettability of distilled water on the material surface. Before the testing, the surface of the test sample was polished with a fine abrasive cloth and polishing cloth under running water, and the surface roughness $(R a)$ of test samples was $0.72 \pm 0.03 \mu \mathrm{m}$. The contact angle of the test sample with distilled water was tested under $23{ }^{\circ} \mathrm{C}$ and humidity $58 \%$ by a water contact angle measurement device (OAC 15EC, Data Physics Instruments Co., Ltd., Germany).

\subsection{Friction and wear}

Under water lubrication conditions, variable velocity friction tests and invariable velocity friction tests were conducted to investigate the tribological behaviour between the friction pairs. Variable velocity friction tests aimed to investigate the effects brought by the change of sliding velocity during the friction process on the tribological behaviour of the friction pairs. Moreover, invariable velocity friction tests were conducted to find the influence of different test parameters on the friction properties of the friction pairs under a constant velocity. The friction and wear tester (MFT-5000, Rtec Instruments Co., Ltd., USA) was used to experimentally evaluate the friction coefficients of test samples against copper balls, seen in Fig. 1.

Because the QSn4-3 copper alloy that contains tin was widely used to make water-lubricated bearing bushings, the QSn4-3 copper ball was adapted to
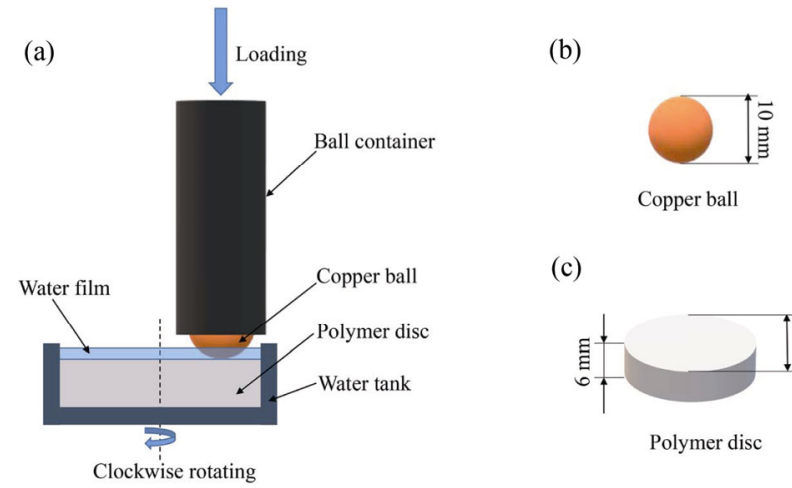

(c)

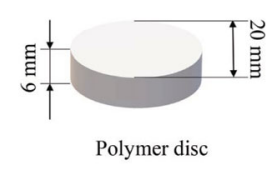

Fig. 1 Schematic illustration of the friction test and the friction pairs: (a) test configuration, (b) copper ball, and (c) polymer disc. establish a ball-on-disc friction pair. As shown in Fig. 1, the copper ball diameter was $10 \pm 0.05 \mathrm{~mm}$. The thickness and diameter of the polymer disc were $6 \pm 0.05 \mathrm{~mm}$ and $20 \pm 0.05 \mathrm{~mm}$, respectively. The polymer discs were polished before testing to a $R a$ of $0.94 \pm 0.05 \mu \mathrm{m}$. An experimental scheme of four sliding velocities of 30,60,90, and $120 \mathrm{~mm} / \mathrm{s}$ was designed for variable velocity experiments under three loads. Four sliding velocities were run for 20 min sequentially under each load. The three loads were set to be 1,5 , and $10 \mathrm{~N}$, the corresponding maximum Hertz contact pressures were $10.9,18.7$, and $23.5 \mathrm{MPa}$, respectively. The invariable velocity experiments were conducted under a load of $30 \mathrm{~N}$ (the maximum Hertz contact pressure $33.9 \mathrm{MPa}$ ) and two velocities of 60 and $120 \mathrm{~mm} / \mathrm{s}$. The testing conditions were adopted according to the measurement range of the friction tester and actual application requirement. All wear tests were repeated three times under the same conditions to guarantee the repeatability of results. Distilled water as a lubricant was added to the surface of the test sample before the tests to form a water-lubricated film. The wear rate $\left(\mathrm{mm}^{3} \cdot \mathrm{N}^{-1} \cdot \mathrm{m}^{-1}\right)$ was calculated from Eq. (1).

$$
\text { Wear rate }=\frac{\text { Volume loss }}{\text { Load } \times \text { Sliding distance }}
$$

\section{Results}

\subsection{Analysis and characterization of microspheres}

In order to investigate the morphologies of the microsphere, different microspheres and fracture sections of their composites were inspected using SEM. As shown in Figs. 2(a)-2(c), the diameter of the microsphere was decreased with the increase of the PAAm content. This could be because PAAm hydrogel has a good swelling ability in the thermodynamically compatible solvent. In the drying process, the water molecules absorbed in the PAAm hydrogel microsphere will escape from the regular meshes of the rubbery network. The expanding rubbery phase starts to shrink and transit to the unsolved glass phase, it will lead to a reduction in volume. The average size of the UF microspheres 

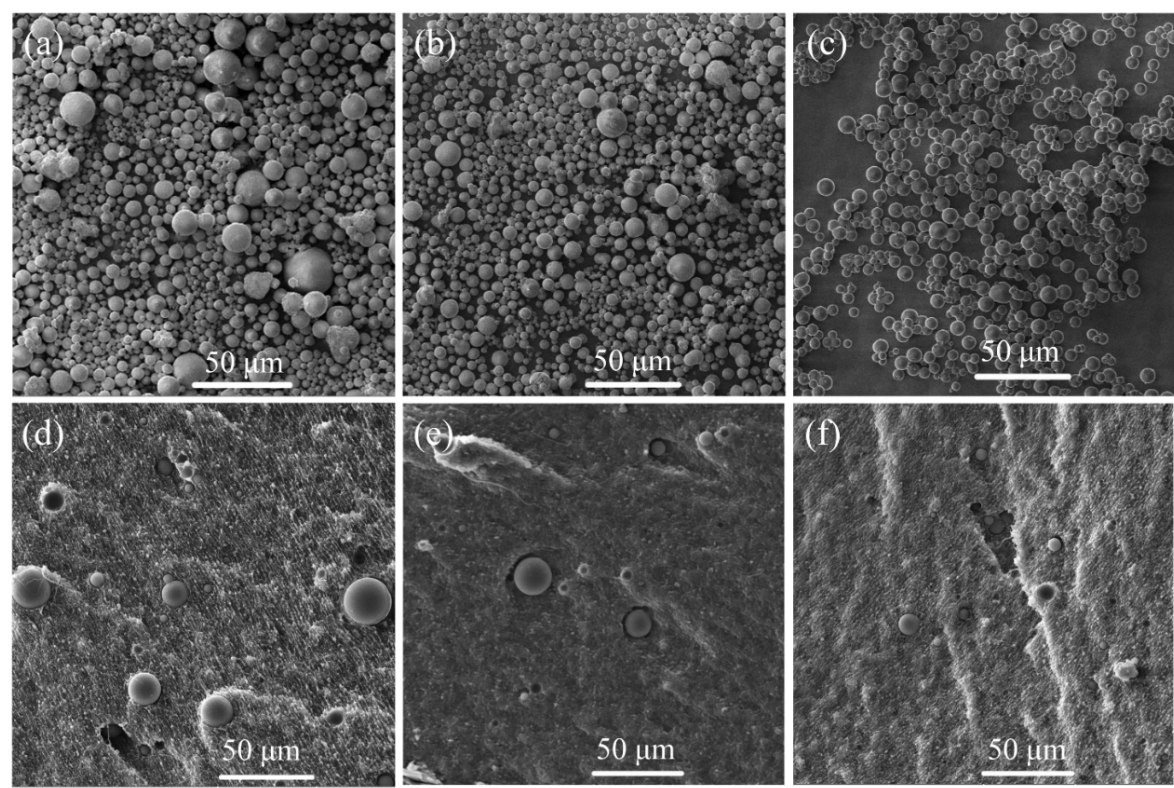

Fig. 2 SEM images of microsphere: (a) UF, (b) 75 DN, and (c) PAAm. Fracture section of the composite samples: (d) UF composite, (e) 75 DN composite, and (f) PAAm composite.

was larger because its hard network has relatively better dimensional stability during drying. For the DN microsphere, the UF hard network limits its deformation and prevents volume shrinkage to some extent. Thus, the diameter of the dried microsphere was decreased with the increase of PAAm content under the same emulsion conditions. It also illustrated that the DN structure is beneficial for good dimension stability in water.

Figures 2(d)-2(f) depict the fracture section images of UF microsphere composite, $75 \mathrm{DN}$ microsphere composite, and PAAm microsphere composite, respectively. All three kinds of microspheres could keep their original spherical shape and size after melt blending and injection molding. All kinds of microspheres could be distributed evenly throughout the composites. That is favorable for the course of processing in practical application.

To investigate the molecular structure, the AAm monomer and microspheres were characterized by the infrared absorption spectrum. As shown in Fig. 3(a), the acrylamide monomer had the strong absorption peak of carbon-carbon double bond at $1,618 \mathrm{~cm}^{-1}$. For PAAm microspheres, the absorption peak at this location disappeared and the absorption peak at $1,605 \mathrm{~cm}^{-1}$ was mainly attributed to amide II $(\delta N H+v C N)$ group. This demonstrated that the double bonds of acrylamide monomer had been cross-linked after polymerization. In the meantime, PAAm microspheres had fewer absorption peak at the spectral range $800-1,300 \mathrm{~cm}^{-1}$ because the highly symmetrical polymer chains made some groups vibrate with inactive infrared absorption. It also proved that acrylamide monomer had been polymerized.

The largest difference between the UF resin and PAAm hydrogel is at the spectral range 3,100$3,300 \mathrm{~cm}^{-1}$. For the UF resin, the single absorption peak at $3,289 \mathrm{~cm}^{-1}$ was attributed to the stretching vibrations of the secondary amine $(\mathrm{NH})$ group. However, the PAAm hydrogel has two characteristic absorption peaks at 3,330 and $3,184 \mathrm{~cm}^{-1}$ that are ascribed to the stretching vibrations of asymmetric and symmetric $\mathrm{NH}_{2}$ in this spectral range. Characteristic absorption peaks at 2,940 and 2,850 $\mathrm{cm}^{-1}$ are ascribed to the stretching vibrations of asymmetric and symmetric $\mathrm{CH}_{2}$, respectively. The absorption peak at $1,380 \mathrm{~cm}^{-1}$ is attributed to the $\mathrm{C}-\mathrm{H}$ stretching vibrations in the $-\mathrm{NHCH}_{2}-$ group. According to the FTIR result, this absorption peak gradually became weaker until it disappeared with the increase of PAAm content. It indicates that the secondary amine $(\mathrm{NH})$ group or UF content in the microsphere was gradually decreased until it disappeared. The absorption peaks could be attributed to the characteristic groups of the amide $\mathrm{I}(\mathrm{vC}=\mathrm{O}+$ 
(a)

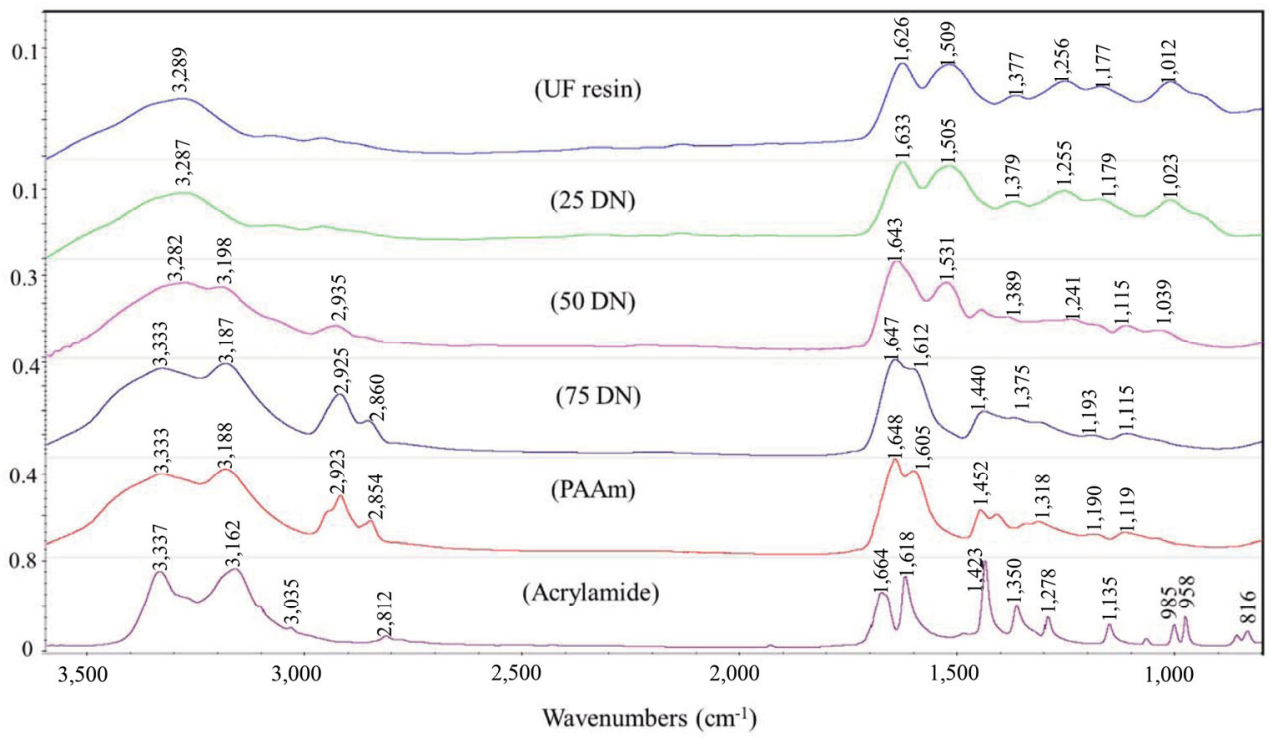

(b)
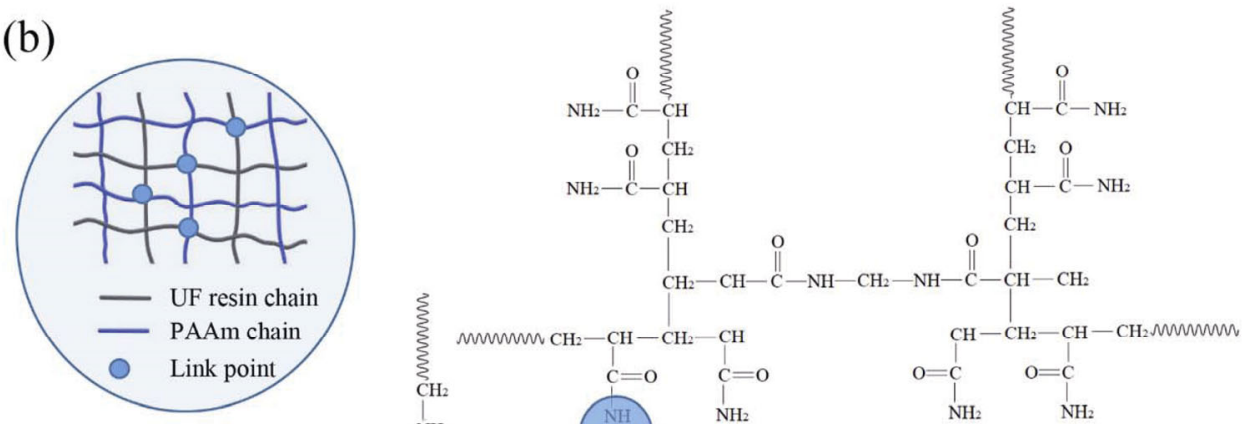

$\underset{\mathrm{O}}{\mathrm{M}}$

Fig. 3 Analysis and characterization of microspheres: (a) infrared spectrum diagram of acrylamide monomer and different microspheres, (b) chemical structure of DN microsphere.

$v \mathrm{CN})$ at $1,626-1,648 \mathrm{~cm}^{-1}$ and amide II $(\delta \mathrm{NH}+v \mathrm{CN})$ at $1,509-1,605 \mathrm{~cm}^{-1}$. The absorption peak wavelength of the reaction products gradually moved to the high wavenumber with an increasing molar ratio of AAm. It is because that more hydrogen bonds were formed due to the increase of $\mathrm{NH}_{2}$ groups in AAm, and the production of more hydrogen bonds had caused the absorption peak to move to high wavenumbers. It also demonstrates that the content of the primary amine $\left(\mathrm{NH}_{2}\right)$ group or PAAm in the microsphere had gradually increased.
Because PAAm possesses in its structure highly reactive amine groups $[26,27]$ that can react with the hydroxyl polymers [28]. Meanwhile, according to Fig. 3(a), the infrared absorption spectroscopy of $25 \mathrm{DN}$ microsphere was almost the same as that of UF resin, and no obvious characteristic absorption peak of the $\mathrm{NH}_{2}$ group was found in its infrared spectra. Therefore, there is a plausible explanation that the $\mathrm{NH}_{2}$ group of AAm or PAAm had reacted with the hydroxyl groups of UF resin prepolymer and formed a stable chemical bond to link the two 
different networks. Both the appearance of two weak absorption peaks at 3,282 and 3,198 $\mathrm{cm}^{-1}$ and the shifting towards the high wavenumber of amide II absorption peak showed that some $\mathrm{NH}_{2}$ groups had appeared in the 50\% DN microsphere after polymerization. For the $75 \%$ DN microsphere, the weak absorption peak at $1,375 \mathrm{~cm}^{-1}$ indicated that there are some $\mathrm{NH}$ groups in the $75 \% \mathrm{DN}$ microsphere. The FTIR results showed that the structure of the reaction product was consistent with the experiment design.

By the comprehensive analysis, the free radical polymerization of PAAm and curing polycondensation of UF resin will react in parallel, and some chemical bonds will be formed to link the soft and hard networks. The chemical structure of the DN microsphere was deduced and summarized follows in Fig. 3(b).

\subsection{Swelling behaviour of microspheres}

In order to analyze dimension stability, the swelling behaviour of different microspheres in distilled water were inspected. Different dry microspheres were soaked in a beaker of distilled water, and the change of the average size of microspheres with different soaking durations was observed by using a 3D digital microscope. The average size and size distribution were obtained by randomly measuring the diameter of at least 100 microspheres for each type imaged by 3D digital microscope. Figure 4

(a)

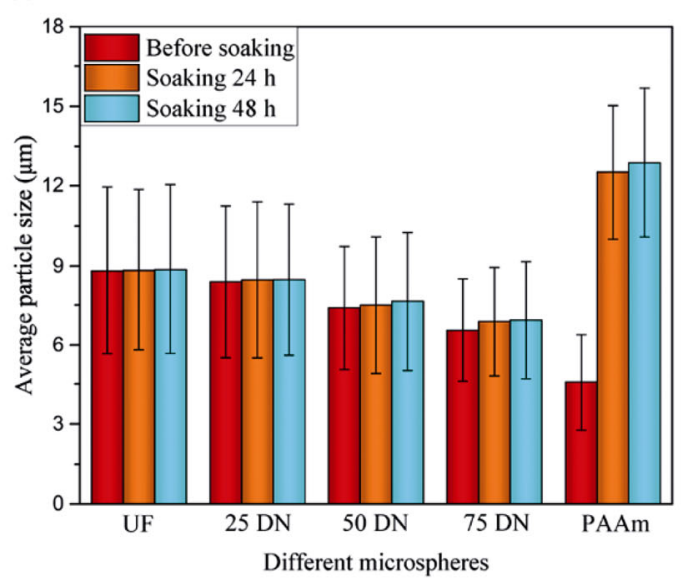

shows the size change of UF, $25 \mathrm{DN}, 50 \mathrm{DN}, 75 \mathrm{DN}$, and PAAm microsphere with deferent soaking durations. It is found that the average size of UF microspheres had no significant changes before and after soaking. Compared with the PAAm microsphere, the average size of DN microspheres could almost remain stable even if the PAAm content was as high as $75 \%$. The result of the change of the average size before and after soaking also indicates that the hard UF network had a good ability to retain dimensional stability of double network in distilled water.

\subsection{Mechanical properties of UHMWPE and its composites}

In order to study the effect of the type and weight content of microsphere on the mechanical properties, UHMWPE and its composites were investigated before and after soaking in distilled water. As shown in Tables 1 and 2, and compared with UHMWPE, the mechanical properties of the four composites with $1 \mathrm{wt} \%$ microspheres had no obvious change irrespective of soaking or not. It illustrates that the four types of microspheres within $1 \mathrm{wt} \%$ did not influence the mechanical properties. However, the mechanical properties of composites reduced when the microsphere content is more than $3 \mathrm{wt} \%$ especially for the tensile strength. Compared with the dry state, the mechanical properties of PAAm-3 and PAAm- 5 were reduced after soaking in distilled (b)

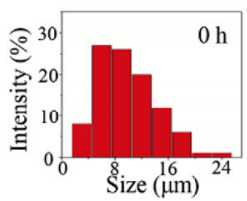

(c)

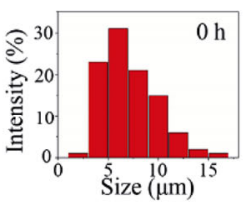

(d)

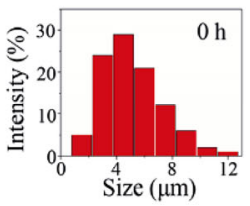

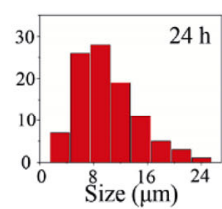
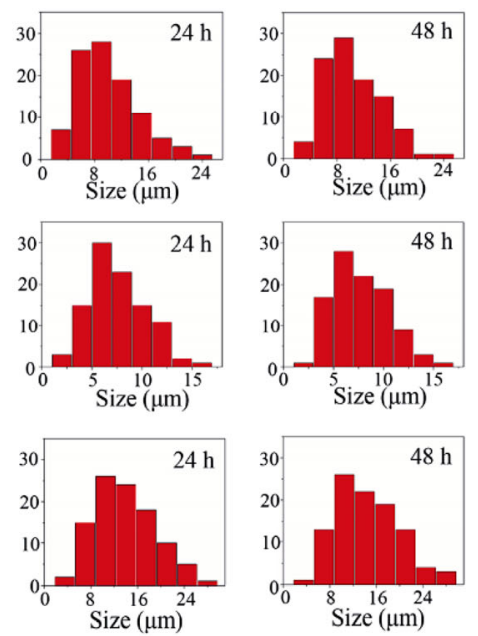

Fig. 4 Particle size of microspheres with different soaking time. (a) Average size of different microspheres. (b-c) Size distribution: (b) UF, (c) $75 \mathrm{DN}$, and (d) PAAm. 
Table 1 Mechanical properties of UHMWPE and its composites without soaking.

\begin{tabular}{|c|c|c|c|c|c|c|c|c|c|c|c|c|c|}
\hline \multirow{2}{*}{ Material } & \multirow{2}{*}{ U-PE } & \multicolumn{3}{|c|}{ UF composite } & \multicolumn{3}{|c|}{$50 \mathrm{DN}$ composite } & \multicolumn{3}{|c|}{75 DN composite } & \multicolumn{3}{|c|}{ PAAm composite } \\
\hline & & $1 \mathrm{wt} \%$ & $3 \mathrm{wt} \%$ & $5 \mathrm{wt} \%$ & $1 \mathrm{wt} \%$ & $3 \mathrm{wt} \%$ & $5 \mathrm{wt} \%$ & $1 \mathrm{wt} \%$ & $3 \mathrm{wt} \%$ & $5 \mathrm{wt} \%$ & $1 \mathrm{wt} \%$ & $3 \mathrm{wt} \%$ & $5 \mathrm{wt} \%$ \\
\hline $\begin{array}{l}\text { Tensile strength } \\
(\mathrm{MPa})\end{array}$ & 22.5 & 22.4 & 21.8 & 20.3 & 22.5 & 21.9 & 20.7 & 22.6 & 21.7 & 20.4 & 22.3 & 21.6 & 20.3 \\
\hline $\begin{array}{l}\text { Bending strength } \\
\qquad(\mathrm{MPa})\end{array}$ & 21.2 & 22.1 & 20.9 & 20.3 & 22.1 & 21.1 & 20.6 & 21.9 & 21.1 & 20.5 & 21.6 & 21.2 & 20.8 \\
\hline $\begin{array}{l}\text { Hardness } \\
\left(\mathrm{N} / \mathrm{mm}^{2}\right)\end{array}$ & 21.3 & 21.7 & 22.6 & 22.9 & 21.9 & 22.7 & 23.0 & 22.3 & 22.8 & 23.1 & 22.2 & 22.8 & 23.1 \\
\hline $\begin{array}{l}\text { Young's modulus } \\
(\mathrm{MPa})\end{array}$ & 1,059 & 1,073 & 1,031 & 977 & 1,088 & 1,019 & 966 & 1,066 & 1,034 & 972 & 1,064 & 1,027 & 961 \\
\hline
\end{tabular}

Table 2 Mechanical properties of UHMWPE and composites with soaking for seven days.

\begin{tabular}{|c|c|c|c|c|c|c|c|c|c|c|c|c|c|}
\hline \multirow{2}{*}{ Material } & \multirow{2}{*}{ U-PE } & \multicolumn{3}{|c|}{ UF composite } & \multicolumn{3}{|c|}{$50 \mathrm{DN}$ composite } & \multicolumn{3}{|c|}{75 DN composite } & \multicolumn{3}{|c|}{ PAAm composite } \\
\hline & & $1 \mathrm{wt} \%$ & $3 \mathrm{wt} \%$ & $5 \mathrm{wt} \%$ & $1 \mathrm{wt} \%$ & $3 \mathrm{wt} \%$ & $5 \mathrm{wt} \%$ & $1 \mathrm{wt} \%$ & $3 \mathrm{wt} \%$ & $5 \mathrm{wt} \%$ & $1 \mathrm{wt} \%$ & $3 \mathrm{wt} \%$ & $5 \mathrm{wt} \%$ \\
\hline $\begin{array}{l}\text { Tensile strength } \\
(\mathrm{MPa})\end{array}$ & 22.7 & 22.5 & 21.6 & 20.4 & 22.4 & 21.7 & 20.4 & 22.6 & 21.6 & 20.7 & 22.1 & 20.8 & 19.5 \\
\hline $\begin{array}{l}\text { Bending strength } \\
(\mathrm{MPa})\end{array}$ & 21.1 & 21.4 & 20.7 & 20.1 & 21.3 & 20.9 & 20.0 & 21.4 & 21.0 & 20.1 & 20.9 & 20.3 & 18.8 \\
\hline $\begin{array}{l}\text { Hardness } \\
\left(\mathrm{N} / \mathrm{mm}^{2}\right)\end{array}$ & 21.4 & 21.5 & 22.1 & 22.3 & 21.7 & 22.3 & 22.8 & 22.2 & 22.6 & 22.9 & 22.0 & 22.1 & 21.7 \\
\hline $\begin{array}{l}\text { Young's modulus } \\
(\mathrm{MPa})\end{array}$ & 1,056 & 1,062 & 1,029 & 961 & 1,053 & 1,007 & 971 & 1,047 & 1,022 & 969 & 1,013 & 981 & 906 \\
\hline
\end{tabular}

water. Other composites could maintain their mechanical properties after soaking.

It shows that DN microsphere composites had more stable mechanical properties than PAAm composites in water. This may be because many micro-defects were produced between the microspheres and the UHMWPE matrix due to their incompatibility. Because of the poor dimension stability, the water-absorbing and softening behavior of PAAm microsphere would magnify the impact of micro-defects. Thus, the decrease in mechanical properties of PAAm microsphere composites was more dramatic after soaking. It also indicates that the UF hard network could effectively maintain the stable performance of DN networks in the water environment even if the content of the PAAm soft network was as high as $75 \%$, which was consistent with the analysis of the swelling behaviour of microspheres.

\subsection{Wettability}

Figure 5 shows the effects of the type and content of the microsphere on the distilled water contact angle of the composite. Compared with pure UHMWPE, all composites had a smaller water contact angle. This indicates that the wettability of composite could be improved by adding UF, DN, or PAAm microsphere. The contact angle of composite showed a downward trend with the increase of microsphere content or PAAm content of microsphere. This illustrates that the PAAm constituent of microsphere had played a more important role in wettability improvement. In particular, the contact angle of the PAAm composite was larger than that of $50 \mathrm{DN}$ or $75 \mathrm{DN}$ composites. It might be because some PAAm microsphere would be lost during

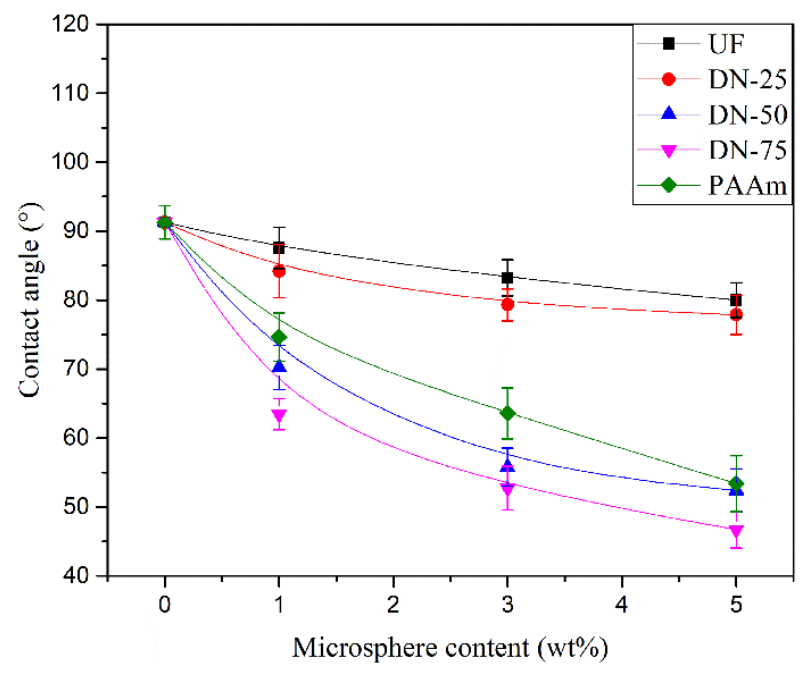

Fig. 5 Effects of type and content of microsphere on the wettability of composite. 
surface treatment of polishing or cleaning due to its absorbing and swelling behaviors.

\subsection{Friction coefficient values}

To analyse the friction behaviour between the copper ball and polymer disc, variable velocity experiments were carried out under three different loads and four different rotating velocities. Figure 6 illustrates the effect of the microsphere, load, and sliding velocity on the friction coefficient between polymer discs and QSn4-3 copper balls.

Generally, the friction coefficient followed a similar decreasing trend as the load increased, as shown in Fig. 6. The friction coefficient changed little as the sliding velocity was changed. It demonstrates that the rubbing pairs have a relatively stable friction coefficient at the low sliding velocities up to $120 \mathrm{~mm} / \mathrm{s}$. Under the low load of $1 \mathrm{~N}$ and low microsphere content of $1 \%$, as shown in Fig. 6(a), the friction coefficient between polymer disc and copper ball decreased as the content of the PAAm hydrogel in microsphere increased. The friction coefficient of the $75 \mathrm{DN}-1$ composites had the almost same friction coefficients as the PAAm-1 composite. Figures 6(a)-6(c) showed that, compared with other microsphere composites, the waterlubricated ability of PAAm microsphere composite did not enhance with the increase of microsphere content, even had been slightly reduced. However, the friction coefficients of $50 \mathrm{DN}$ and $75 \mathrm{DN}$ composites showed a decreasing trend as the microsphere content increased. It indicates that 50 DN and 75 DN composites had a good waterlubricated capacity under low load, even in a high microsphere content.

As shown in Fig. 6(d), a similar decreasing trend of the friction coefficient between $1 \%$ composite disc and copper ball with increase of PAAm content in microsphere was observed under the load of $5 \mathrm{~N}$. But the PAAm-3 and PAAm-5 had higher friction
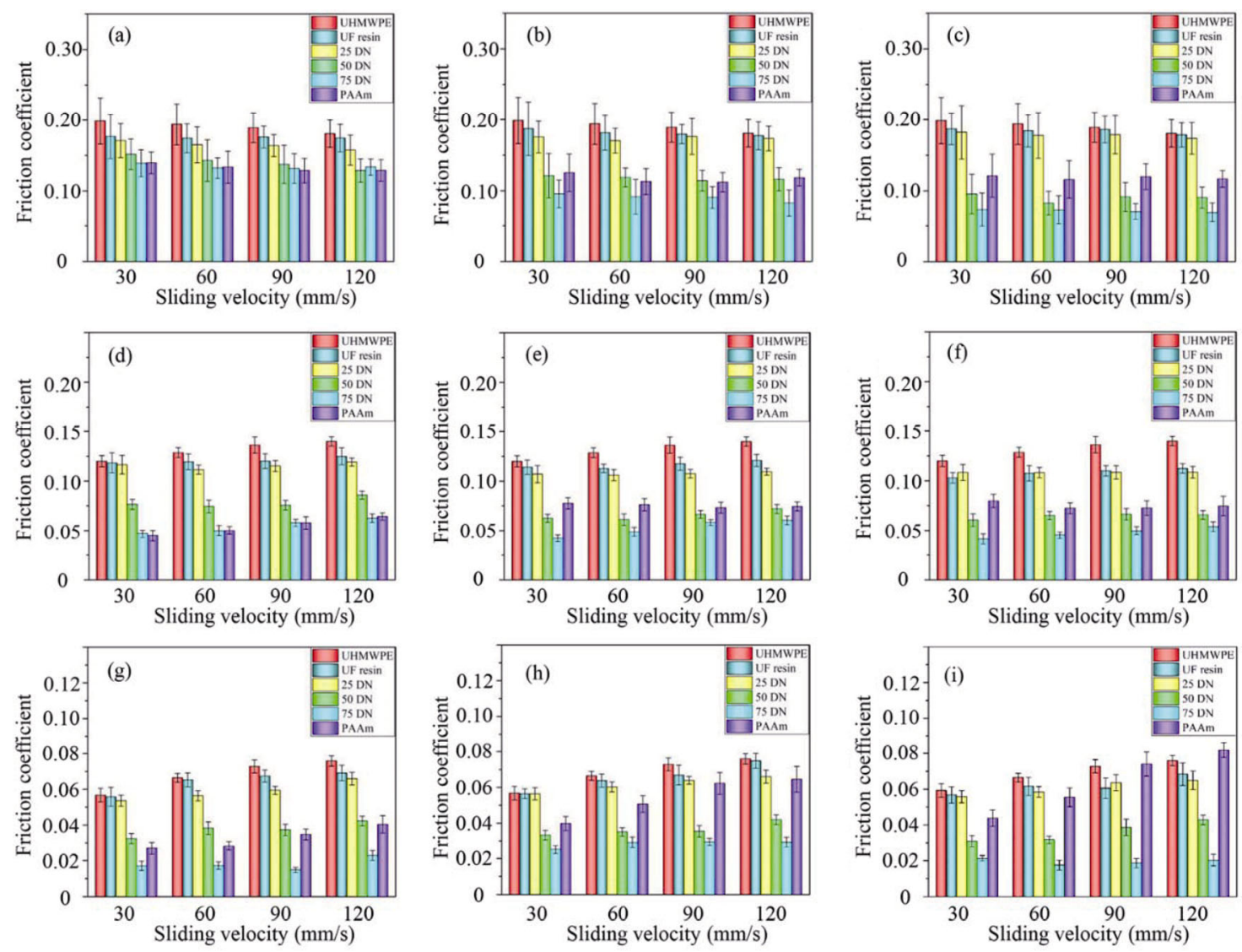

Fig. 6 Friction coefficients of UHMWPE and composites under different loads and microsphere contents: (a-c) 1 N, (d-f) 5 N, and (g-i) $10 \mathrm{~N}$; (a, d, g) $1 \mathrm{wt} \%$ microsphere, (b, e, h) $3 \mathrm{wt} \%$ microsphere, and (c, f, i) $5 \mathrm{wt} \%$ microsphere. 
coefficients than that of $50 \mathrm{DN}$ and $75 \mathrm{DN}$ composites with the same microsphere content, as shown in Figs. 6(e) and 6(f). Under the load of $10 \mathrm{~N}, 50 \mathrm{DN}$ and $75 \mathrm{DN}$ composites could have better performance than other polymers under experiment conditions, as shown in Figs. 6(g)-6(i). In addition, the friction coefficient of PAAm composite was increased with the increasing of microsphere content and was even higher than that of UHMWPE when the PAAm microsphere content was $5 \mathrm{wt} \%$. These results clearly show that the DN structure of the microsphere was beneficial for stable lubrication under high load.

For a better understanding of the lubrication behaviors under the constant velocities, invariable velocity experiments were carried out under the load of 30 N. Figure 7 showed that the comparison in terms of friction coefficients of polymer samples under the sliding velocity of 60 and $120 \mathrm{~mm} / \mathrm{s}$. In the beginning stage, the friction coefficient of polymer samples increased slightly, which is usually called as the running-in or break-in period. This is because irreversible deformations of some micro-bulges on the sliding surfaces will result in a high friction resistance during the beginning period. As testing progresses, the friction coefficients decreased rapidly and finally tended to a steadystate. As shown in Fig. 7, compared with the 50 DN-3 composite, the 70 DN-3 composite had a smaller friction coefficient. This demonstrates that more soft PAAm content in the microsphere was a benefit for the effective and stable lubrication film. However, the friction coefficient of PAAm-3 firstly

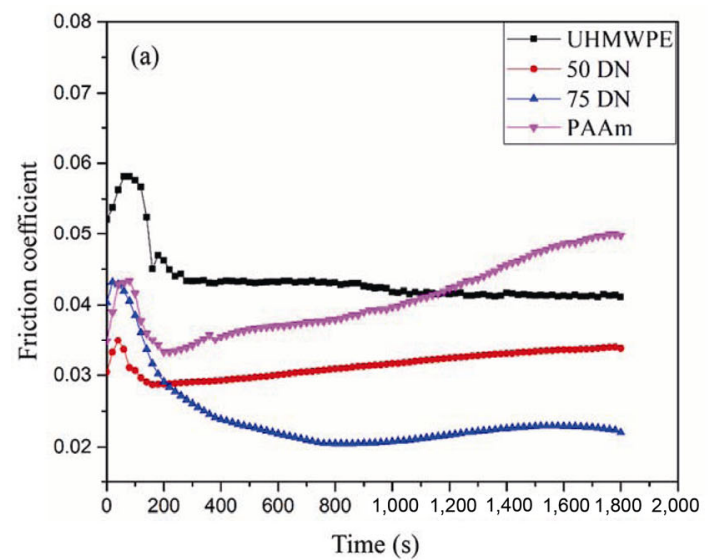

decreased and then increased with testing time increasing. This could be because the swelling of PAAm microsphere will lead to its crushing and peeling during rubbing, and leave many defects on the surface. The damage will become more serious with the increase of testing time and result in a rapid increase in friction coefficient. Therefore, the friction coefficient of PAAm composite was bigger than that of UHMEPE at the end of testing.

\subsection{Wear rate}

Figure 8 shows the wear rate of polymer discs versus different experiment parameters. In this work, the wear rate was calculated by Eq. (1). As shown, the type or content of the microsphere and experimental load influenced the wear performance of the composite. In general, the wear rate increased with increasing experimental load. It is because that increased radial load led to more serious asperity truncation and plough effects, which caused more abrasion wear during the rubbing. Therefore, the wear and tear were accelerated under high contact stress.

Compared with other polymer discs, both 50 $\mathrm{DN}$ and $75 \mathrm{DN}$ microsphere composites have good abrasion resistance while the wear rate of $75 \mathrm{DN}$ samples was the smallest. It also showed that, for the three DN microsphere composites, the wear rate was decreased with the PAAm content in microspheres increasing under the same conditions. The experimental results also showed that the $75 \mathrm{DN}-1$ composite had the optimum wear-resistance property. For the

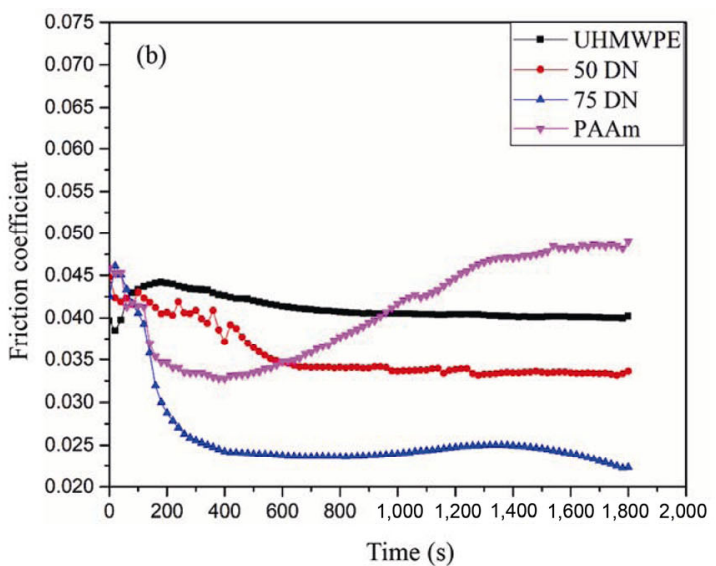

Fig. 7 Changing of friction coefficients with time under different test conditions: (a) $30 \mathrm{~N}$ and $60 \mathrm{~mm} / \mathrm{s}$, (b) $30 \mathrm{~N}$ and $120 \mathrm{~mm} / \mathrm{s}$. 

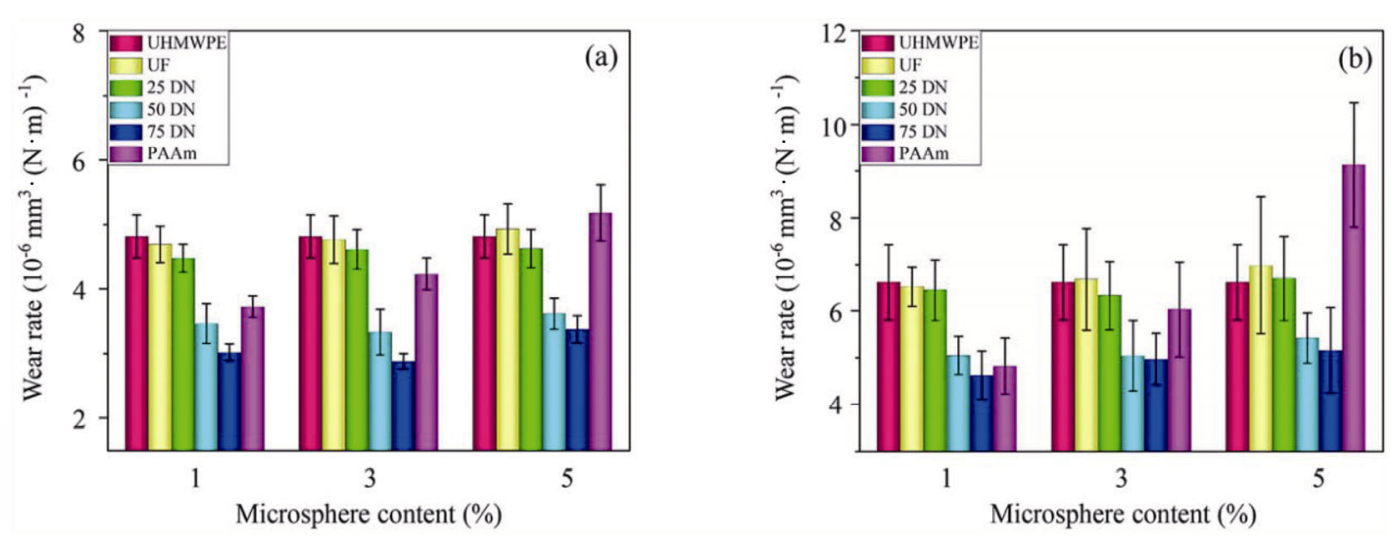

Fig. 8 Wear rate of polymer discs under different applied loads: (a) $5 \mathrm{~N}$ and (b) $10 \mathrm{~N}$.

UF composite and PAAm composite, the bigger the ratio of the microsphere is, the worse the antifriction performance of the composite is.

\subsection{Wear surface topographies}

In order to analyze the effect of different microspheres on wear behaviour of the polymer discs and QSn4-3 copper balls further, the wear surface topographies were analyzed using the laser scanning confocal microscope. Figures 9 and 10 display the effect of microsphere on the wear surface topography of composite with $1 \mathrm{wt} \%$ microspheres under the applied loads of 5 and $10 \mathrm{~N}$.

(a)

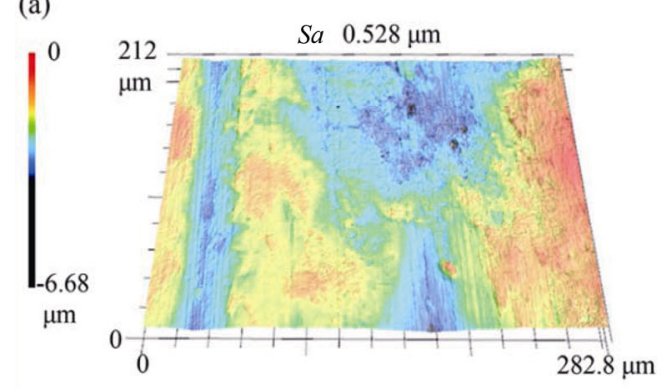

(c)

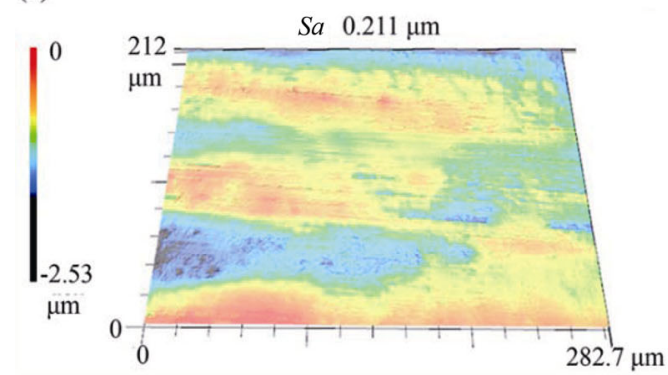

As shown in Figs. 9 and 10, many obvious furrows and crests were observed on the wear surface of the polymer discs after wear testing, which indicates that abrasive wear is the dominant wear mechanism. Furthermore, furrows and crests on the wear surface of the UHMWPE disc are wider and deeper than that of other composite discs. In Figs. 9(b) and 9(c), it is shown that $50 \mathrm{DN}$ and $75 \mathrm{DN}$ microspheres could firmly be embedded in the UHMEPE matrix and had been worn off simultaneously with UHMWPE matrix during the rubbing process under $5 \mathrm{~N}$ load. However, in Figs. 10 (b) and 10(c), the $50 \mathrm{DN}$ microsphere could crush

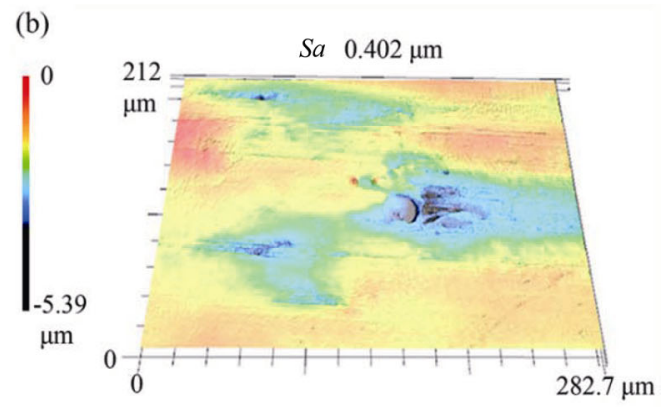

(d)

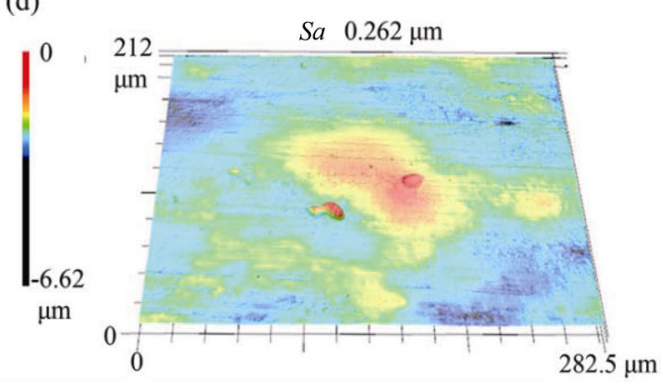

Fig. 9 3D wear surface topographies of polymer discs after the variable velocity tests under 5 N: (a) UHMWPE, (b) 50 DN, (c) $75 \mathrm{DN}$, and (d) PAAm. 

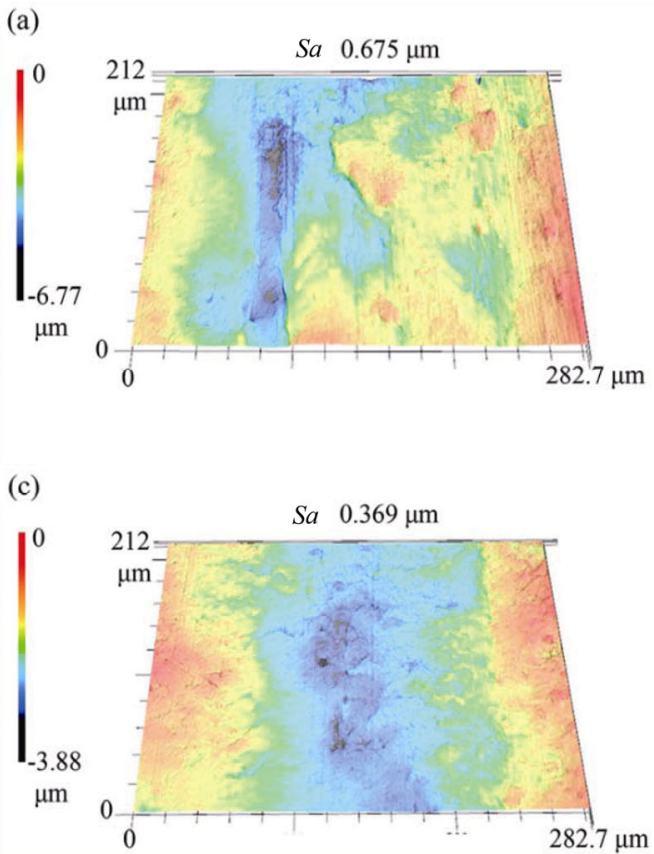

(b)

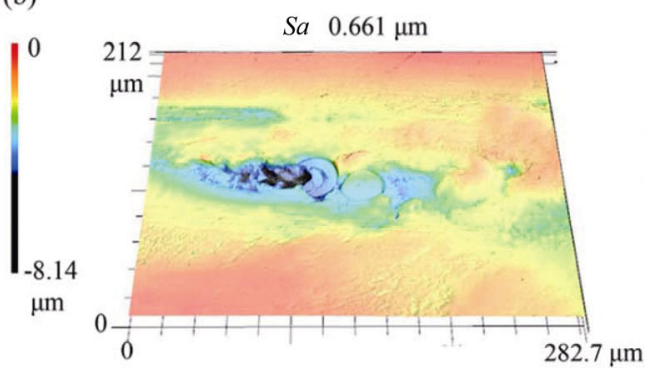

(d)

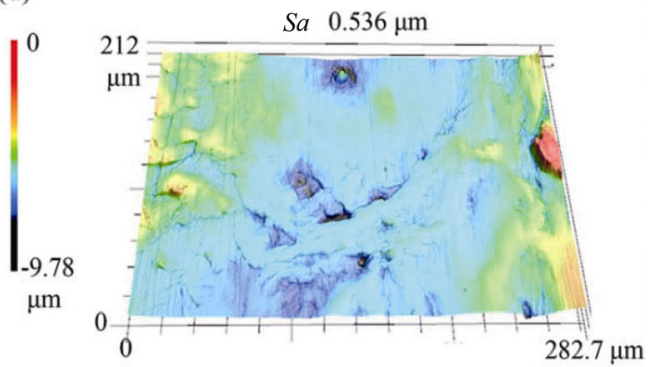

Fig. $103 \mathrm{D}$ wear surface topographies of polymer discs after the variable velocity tests under $10 \mathrm{~N}$ : (a) UHMWPE, (b) 50 DN, (c) $75 \mathrm{DN}$, and (d) PAAm.

under the load of $10 \mathrm{~N}$, and the $75 \mathrm{DN}$ microsphere did not break during the rubbing under the same load. This might be that the higher proportion of soft PAAm rubbery phase had guaranteed for the 75 DN microsphere's strong toughness. As shown in Fig. 10(d), there were some micro-defects on its friction surface under the load of $10 \mathrm{~N}$. It demonstrates that the micro-holes caused by the PAAm microspheres peeling would lead to further destruction of the composite surface under the load of $10 \mathrm{~N}$.

Figure 11 shows the cross-sectional profiles of worn regions and 3D morphologies of UHMWPE, $50 \mathrm{DN}, 75 \mathrm{DN}$, and PAAm composite, respectively. Before the observation, polymer discs were cleaned ultrasonically with distilled water and alcohol, respectively. As shown in Fig. 11(a), the worn region of UHMWPE had many obvious cracks and furrows, and was much rougher than other composites. Figures 11(b)-11(e) indicated that the $75 \mathrm{DN}$ microsphere could provide the best separation and protection for the wear surface of polymer disc. In Fig. 11(e), it was also found that the peeling of PAAm microspheres left some micro-holes on the rubbing surface, the micro-holes would further damage to the rubbing surface and formed some bigger linear wear zones, although the protection of PAAm fragments could make some parts of the wear region smoother than that of UHMWPE.

\section{Discussion}

\subsection{Analysis of swelling mechanism}

The water molecule $\left(\mathrm{H}_{2} \mathrm{O}\right)$ has a great electric dipole because of its asymmetric structure of positive and negative electrical charges [12]. Meanwhile, the PAAm hydrogel is characterized by charge density, and the charged chains will attract water molecules, as shown in Fig. 12. The PAAm hydrogel could absorb the running water between the friction pairs and form a water lubricating film on the interface, and ultimataly acts as a good water lubricator [29]. The super water-absorbing capability of PAAm hydrogel materials leads to excellent hydration lubrication properties. However, the swelling behavior of PAAm can bring an unfavorable effect on friction and wear properties of the composite when using water as a lubricant.

Figure 12(a) explains the absorbing and swelling behaviour of the PAAm microspheres. As well known, the PAAm hydrogel is a typical soft-solid 
(a)

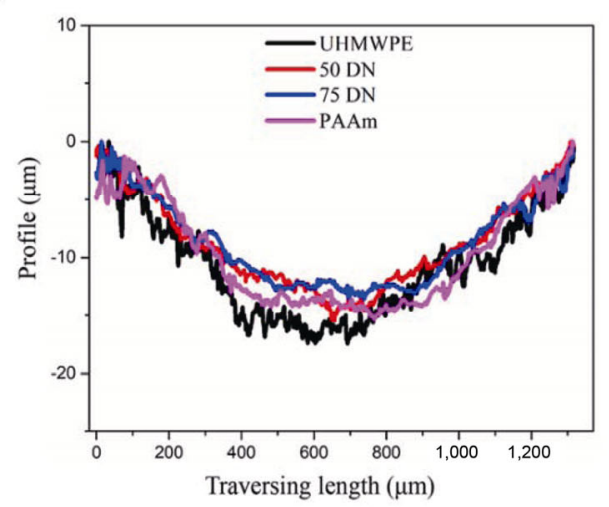

(b)

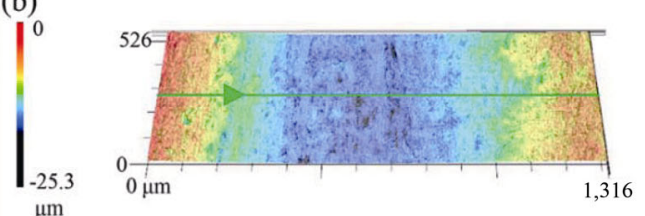

(c)

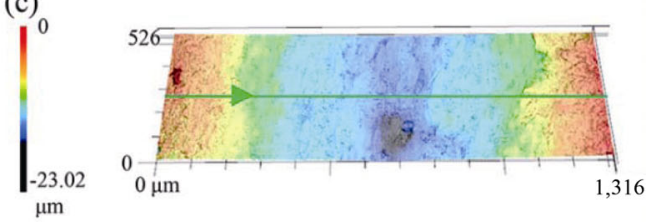

(d)

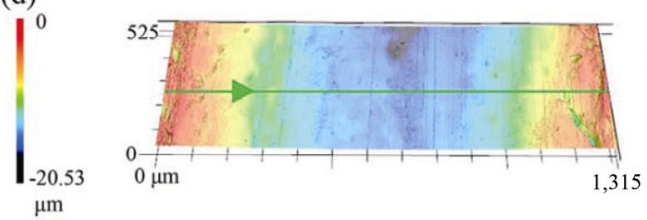

(e)

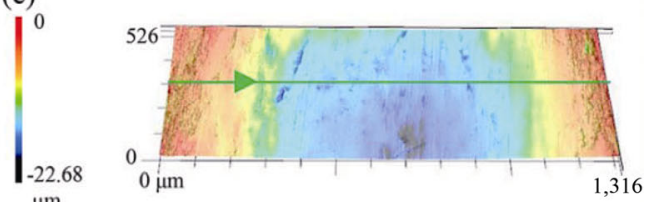

Fig. 11 (a) Cross-sectional profiles and (b-e) 3D wear surface topographies of the polymer discs under sliding velocity of $120 \mathrm{~mm} / \mathrm{s}$ and load of $30 \mathrm{~N}$ : (b) UHMWPE, (c) $50 \mathrm{DN}$, (d) $75 \mathrm{DN}$, and (e) PAAm.

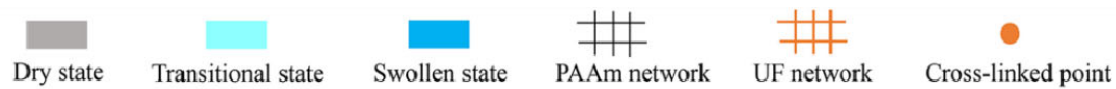

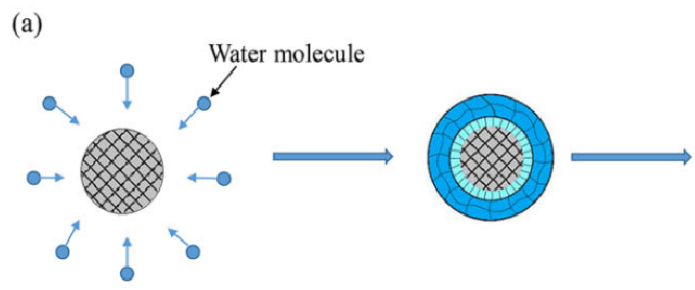

Dry PAAm microsphere

(b)

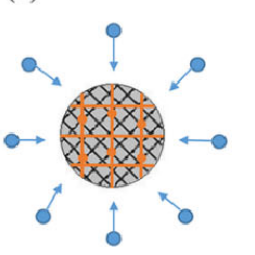

Dry DN micorosphere

Swelling PAAm microsphere

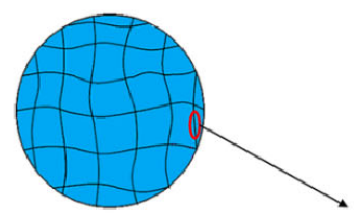

Swollen PAAm microsphere
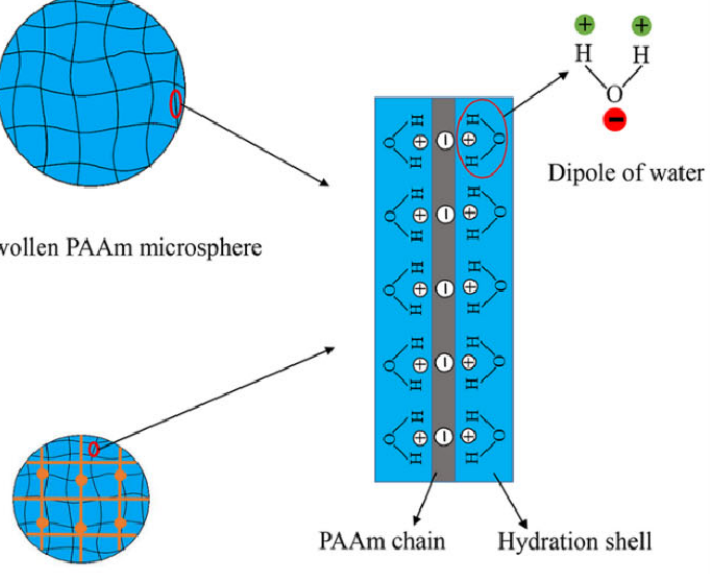

Dipole of water

Swollen DN microsphere

Fig. 12 Schematic illustration of swelling process of microsphere: (a) PAAm microsphere and (b) DN microsphere.

material with hydrophilic groups in the 3D network structure. In the dry state, the stable structure of a 3D cross-linked net can limit the movement of the molecular chain, and the volume of the microsphere is relatively small. When it is in contact with distilled water, water molecules start to attack the PAAm microsphere surface [30]. The hydrogen bond between the charged polar group and the water molecule would cause the water molecule to tenaciously attach to the PAAm chain, and form a hydration shell around the chain [12]. Meanwhile, dissociated polymer ion chains with the hydration shell are negatively charged (Fig. 12), the electrostatic repulsion can make polymer chains extend and lead to spatial expansion of the entire network structure. This expansion is beneficial for allowing 
free water molecules to diffuse into the hydrogel material. The water molecules gradually penetrate inside the 3D network structure of PAAm microspheres. Simultaneously with absorbing and swelling, an opposite elasticity force will balance the stretching of the network and prevent its deformation. The swelling is dynamically balanced when the elasticity and osmotic forces are equal [30]. The swelling particle eventually reaches the swollen state.

For better dimensional stability, the UF resin hard network is introduced into the PAAm soft network to form a double-network structure. According to Fig. 4, compared with the PAAm microsphere, the average size of soaked DN microsphere has changed very little. It proves that the strong hard network can effectively control swelling deformation of the microsphere in water. A small increase of the average size of soaked DN microsphere demonstrates that the PAAm soft network in the double network has a certain hydration ability in water. The swelling process of the DN microsphere is analyzed in Fig. 12(b). When it is in contact with distilled water, water molecules will also start to attack the DN microsphere surface. The hydrogen bond between the soft PAAm network and water molecules can make the water molecule penetrate the DN microspheres, and form a hydration shell around the soft PAAm chain. The hard UF network will not become soft in water, and it has enough strength to limit the spatial expansion of the PAAm network. Meanwhile, the cross-points between the two networks have further control of the extension of polymer chains. Therefore, the DN microsphere can have better dimensional stability in water.

\subsection{Analysis of lubrication mechanism}

As is well known, the PAAm hydrogel material has many unique characteristics in water solutions. The absorbing and swelling characteristics of PAAm will have two different effects on its application for tribological fields. On one hand, the hydration layer around the PAAm chains will result in excellent hydration lubrication performance, which is beneficial to decrease the friction coefficient and protect wear surfaces [31]. On the other hand, the swelling behaviour of the hydrogel in water will bring some unfavorable influences for dimensional stability and mechanical strength. This will be some fatal flaws for engineering applications.

For making the best advantage and avoiding the disadvantages, the hard/soft double network strategy will be an effective solving approach [32]. In this strategy, the PAAm soft network can ensure excellent lubrication and the UF hard network is used to control the deformation of the PAAm soft network in water. The friction behaviour of polymer samples is illustrated in Fig. 13. The SEM images at the right show a convincing check of the validity of the model assumptions. In addition, PAAm or DN hydrogel fragments are identified by the characteristic elements of nitrogen that was evaluated by energy spectrum analysis.

Figure 13(a) shows the friction behaviors of the UHMWPE sample under water lubrication. Because of the low viscosity of water, the waterlubricating film between the UHMWPE disc and copper ball cannot be effectively formed during rubbing, especially under heavy load. The rough surfaces of friction pairs will be direct contact under load. The plastic deformation, viscous effects, and wear caused by copper ball relative motion with UHMWPE disc will result in a higher frictional resistance and a more serious wear extent. Therefore, the friction coefficient and wear loss mass of UHMWPE disc are larger than that of others under the most experimental conditions.

Due to the absorbing and brittle characteristics, the PAAm microspheres will swell, peel off, and then break up into many tiny fragments by the shearing force in the rubbing process (Fig. 13(b)). Those PAAm hydrogel fragments will randomly distribute on the contact surface between friction surfaces and form a dynamic hydration lubrication layer during rubbing. Meanwhile, it also leaves many micro-defects on the contact surface and damages the wear surface smoothness, which will lead to higher friction resistance and abrasion loss. 


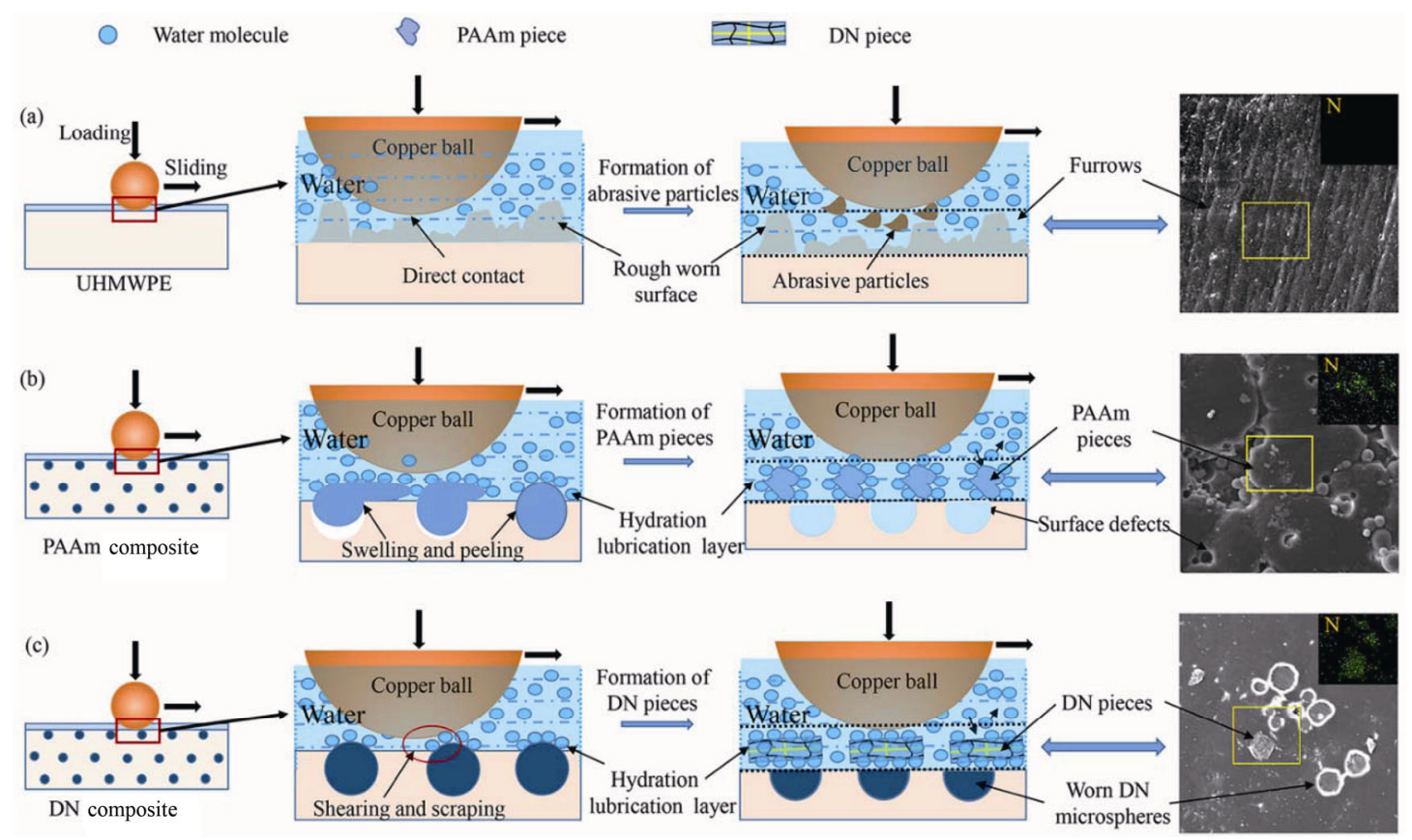

Fig. 13 Schematic illustration of friction behavior in rubbing process: (a) UHMWPE, (b) PAAm microsphere composite, and (c) DN microsphere composite.

Under low load, the number and extent of the defect are usually not obvious influence on the friction properties of PAAm microsphere composite, the hydration lubrication of PAAm fragments play an important role in the rubbing. Therefore, the friction coefficient, wear mass loss, and surface roughness of PAAm microsphere composite are better than that of UHMWPE. However, with the increasing of testing load, the unfavorable influence of surface defect will become more serious. The adverse effects of surface defects on friction properties will be dominant across the rubbing process and result in a worse friction coefficient, wear mass loss, and surface roughness than UHMWPE.

The design strategy of the hard/soft DN structure had already been proved to be an effective solution for this problem. In the strategy, the hard network can ensure the microspheres with good dimensional stability and high strength. The DN microspheres in the composite will be not damaged and can help to smooth the contact surface in the rubbing process with a normal load. The DN microspheres on the rubbing surface are scraped off one layer at a time and leave many worn DN microspheres worked as micro hydration lubrication supplies in the lubricating process. DN microsphere layers will break into many tiny pieces under shear force, and form a hydration lubricating film on the worn surface. Meanwhile, the absorbing DN pieces are just one dynamic equilibrium state about the movement of water molecules toward charged polymer chains on time average. Water molecules absorbed on charged PAAm chains of the DN layer are not statically invariable. They not only can move quite quickly in the hydration shell but also can exchange very rapidly with those water molecules outside of the hydration shell [12], as Fig. 13(c) shows. This characteristic makes the DN hydration films work like a slippery solid ice surface with thin water film when shear movement occurs. Thus, the DN film on the rubbing track could provide very low friction resistance when the copper ball slides on the composite sample. Meanwhile, because of the mechanical supporting role of the UF hard network, both $50 \mathrm{DN}$ and $75 \mathrm{DN}$ microsphere composites have a superior lubrication property even under heavy load. Therefore, the $50 \mathrm{DN}$ and $75 \mathrm{DN}$ microsphere composites have excellent antifriction and waterlubricated performance under the test conditions. The protective effect of DN film also can effectively 
reduce wear and result in a relatively smooth surface. Water molecules in the hydration layer of PAAm have good dynamic stability in a wide range of normal press and sliding velocity due to the large dehydration energy [12]. This is helpful for the composite to obtain excellent comprehensive properties under the experimental conditions.

The results also indicates the relations among friction coefficient, wear mass loss, and the wear surface topography of composites with the different PAAm content in DN microspheres. The friction and wear performance of UF and $25 \mathrm{DN}$ microsphere composite are slightly better than that of UHMWPE due to their limited wetting capacity, as shown in Fig. 5. With the increase of PAAm content in microsphere, the soft feature of PAAm network will protect the microsphere from damage during rubbing, and the hydration capacity of the microsphere is an improvement. Figures 7 and 8 show that the $50 \mathrm{DN}$ and $75 \mathrm{DN}$ composite have good friction and wear performance. This is because that the $50 \mathrm{DN}$ and $75 \mathrm{DN}$ microspheres possess both high stability of the UF hard network and excellent water-lubricated performance of the PAAm soft network. Appropriate concentration of hard network can be effectively limited swelling of the two types of DN microspheres and offer superior load bearing capabilities. Meanwhile, these two DN microspheres can also provide effective and stable lubrication capacities due to the hydration interaction of the sufficient PAAm soft network. Furthermore, the $75 \mathrm{DN}$ microsphere has the higher ductility and lubrication performance than $50 \mathrm{DN}$ microsphere under high loads. In order to investigate the impact of further increasing of PAAm content, the DN microspheres with $90 \%$ PAAm content (90 DN) has been prepared and tested. According to the experimental results, the overall performance of $90 \mathrm{DN}$ microsphere is very similar to that of PAAm microsphere. It indicates that too little UF hard network is not sustainable to keep the DN microsphere stable in water. Therefore, 75 DN microsphere has the better component ratio to get a good water lubrication capacity under the experiment conditions.

\section{Conclusions}

In this work, a strategy of hard-soft DN microsphere was designed to possess both the good dimension stability of the hard UF network and the excellent hydration lubrication of soft PAAm network, and their absorbing and swelling behaviors were analyzed and investigated. The effects of different microspheres on the friction and wear properties of composites were examined. Excellent waterlubricated properties of the DN microsphere are verified by experimental results. The main conclusions of the present paper can be drawn as follows:

1) All microspheres prepared by emulsion polymerization exhibited regular spherical shape and could keep its original shape after melt blending and injection molding.

2) DN microsphere has a microstructure of two networks that are linked together by chemical bonds. This microstructure ensures that the DN microsphere can possess both the good dimension stability of the hard UF network and the excellent hydration lubrication of the soft PAAm network.

3) By comprehensive consideration of the mechanical performances and the water lubricated capacity, the optimum content of the microsphere in composite is $1 \mathrm{wt} \%$.

4) The overall friction properties of the composite can be significantly enhanced by adding DN microspheres under water lubrication, the lubrication stability of $50 \mathrm{DN}$ and $75 \mathrm{DN}$ microspheres was stronger than PAAm microsphere.

5) Rubbing pairs of 75-1 DN composite disc/ copper pin have the best comprehensive performance under the applied testing conditions.

\section{Acknowledgements}

This work was supported by the National Natural Science Foundation of China (51605248 and 51509195).

Open Access This article is licensed under a Creative Commons Attribution 4.0 International License, which permits use, sharing, adaptation, distribution and reproduction in any medium or format, as long as you give appropriate credit to 
the original author(s) and the source, provide a link to the Creative Commons licence, and indicate if changes were made.

The images or other third party material in this article are included in the article's Creative Commons licence, unless indicated otherwise in a credit line to the material. If material is not included in the article's Creative Commons licence and your intended use is not permitted by statutory regulation or exceeds the permitted use, you will need to obtain permission directly from the copyright holder.

To view a copy of this licence, visit http://creativecommons.org/licenses/by/4.0/.

\section{References}

[1] Li H, Wang J H, Gao S, Chen Q, Peng L M, Liu K H, Wei X L. Super lubricity between $\mathrm{MoS}_{2}$ monolayers. Adv Mater 29: 1701474 (2017)

[2] Holmberg K, Andersson P, Erdemir A. Global energy consumption due to friction in passenger cars. Tribol Int 47: 221-234 (2012)

[3] Nosonovsky M. Oil as a lubricant in the ancient middle east. Tribol Online 2: 44-49 (2007)

[4] Lu X B, Khonsari M M, Gelinck E R M. The Stribeck Curve: Experimental results and theoretical prediction. Trans ASME J Tribol 128: 789-794 (2006)

[5] Briscoe W H, Titmuss S, Tiberg F, Thomas R K, Mcgillivray D J, Klein J. Boundary lubrication under water. Nature 444: 191-194 (2006)

[6] Rotzetter A C C, Kellenberger C R, Schumacher C M, Mora C, Grass R N, Loepfe M, Luechinger N A, Stark $\mathrm{W}$ J. Combining phosphate and bacteria removal on chemically active filter membranes allows prolonged storage of drinking water. Adv Mater 25: 6057-6063 (2013)

[7] Ye X Y, Ma L M, Yang Z G, Wang J Q, Wang H G, Yang $S$ R. Covalent functionalization of fluorinated graphene and subsequent application as water-based lubricant additive. ACS Appl Mater \& Inter 8: 7483-7488 (2016)

[8] Chen F F, Zhu Y J, Xiong Z C, Sun T W, Shen Y Q, Yang R L. Inorganic nanowires-assembled layered paper as the valve for controlling water transportation. ACS Appl Mater \& Inter 9: 11045-11053 (2017)

[9] Guo Z W, Yuan C Q, Liu A X, Jiang S. Study on tribological properties of novel biomimetic material for water-lubricated stern tube bearing. Wear 376: 911-919 (2017)

[10] Yuan C Q, Guo Z W, Tao W, Dong C L, Bai X Q. Effects of different grain sized sands on wear behaviours of NBR/casting copper alloys. Wear 384: 185-191(2017)

[11] Xu Y F, Liu Z C, Dearn K D, Dong Y H, You T, Hu X G. Thermo-tribological behaviour of microgels for improved aqueous lubrication for steel/UHMWPE contact. Tribol Int 130: 63-73 (2019)

[12] Klein J. Hydration lubrication. Friction 1: 1-23 (2013)

[13] Wang C B, Bai X Q, Dong C L, Guo Z W, Yuan C. Q. Friction properties of polyacrylamide hydrogel particle/ HDPE composite under water lubrication. Polymer 180: 121703 (2019)

[14] Huang T, Xu H G, Jiao K X, Zhu L P, Brown H R, Wang H. L. A novel hydrogel with high mechanical strength: A macromolecular microsphere composite hydrogel. $A d v$ Mate 19: 1622-1626 (2007)

[15] Zhang R, Feng Y G, Ma S H, Cai M R, Yang J, Yu B, Zhou F. Tuning the hydration and lubrication of the embedded load-bearing hydrogel fibers. Langmuir 33(9): 2069-2075 (2017)

[16] Yang Y Y, Wang X, Yang F, Shen H, Wu D C. A universal soaking strategy to convert composite hydrogels into extremely tough and rapidly recoverable double-network hydrogels. Adv Mater 28: 7178-7184 (2016)

[17] Lucas A D A, Ambrósio J D, Otaguro H, Costa L C, Agnelli J A M. Abrasive wear of HDPE/UHMWPE blends. Wear 270: 576-583 (2011)

[18] Khalil Y, Kowalski A, Hopkinson N. Influence of energy density on flexural properties of laser-sintered UHMWPE. Addit Manuf 10: 67-75 (2016)

[19] Raffi N M, Srinivasan V. A study on wear behavior of $\gamma$-UHMWPE sliding against 316L stainless steel counter face. Wear 306: 22-26 (2013)

[20] Guezmil M, Bensalah W, Mezlini S. Effect of biolubrication on the tribological behavior of UHMWPE against M30NW stainless steel. Tribol Int 94: 550-559 (2016)

[21] Garcia-Garcia A, Alvarez-Vera M, Montoya-Santiyanes L, Dominguez-Lopez I, Montes-Seguedo J, Sosa-Savedra J, Barceinas-Sanchez J D O. Regression models to predict the behaviour of the coefficient of friction of AISI $316 \mathrm{~L}$ on UHMWPE under ISO 14243-3 conditions. $J$ Mech Behav Biomed 82: 248-256 (2018)

[22] Yan Z M, Zhou X C, Qin H L, Niu W Y, Wang H, Liu K, Tang Y. M. Study on tribological and vibration performance of a new UHMWPE/graphite/NBR water lubricated bearing material. Wear 332: 872-878 (2015)

[23] Liu C Z, Ren L Q, Arnell R D, Tong J. Abrasive wear behavior of particle reinforced ultrahigh molecular weight polyethylene composites. Wear 225: 199-204 (1999)

[24] Xiong C X, Chen T, Dong L J, Nan W H. Study on 
properties of kaolin/quardrupedal crystal whisker of zinc oxide co-filled UHMWPE. J Wuhan Univ Technol 27: 1-3 (2005) (in Chinese)

[25] Tong J, Ma Y H, Arnell R D, Ren L Q. Free abrasive wear behavior of UHMWPE composites filled with wollastonite fibers. Compos Part A: Appl S 37: 38-45 (2006)

[26] Zhang M, Li B C, Chen L B. Fabrication of IPNpoly(acrylamide)/chitosan composite macroporous cryogels and adsorption of methylene blue. New Chem Mater 42: 166-168 (2014)

[27] Samanta H S, Ray S K. Synthesis, characterization, swelling and drug release behavior of semi-interpenetrating network hydrogels of sodium alginate and polyacrylamide. Carbohyd Polym 99: 666-678 (2014)

[28] Das R, Panda A B, Pal S. Synthesis and characterization of a novel polymeric hydrogel based on hydroxypropyl

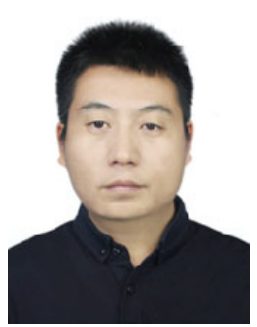

Chaobao WANG. He received his B.S. degree in polymer materials science and engineering at Jilin Jianzhu University in 2007 and M.S. degree in polymer chemistry and physics at Changchun University of Technology in 2010. He has

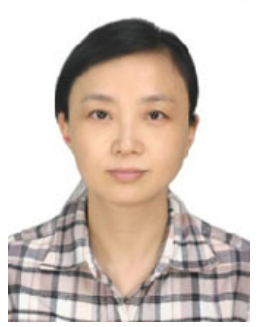

Xiuqin BAI. She received her M.S. degree in vehicle operating engineering at Wuhan University of Technology in 1997 and Ph.D. degree in mechanical design and theory at Wuhan Research Institute of Materials Protection, China Academy of Machinery Science and Technology in

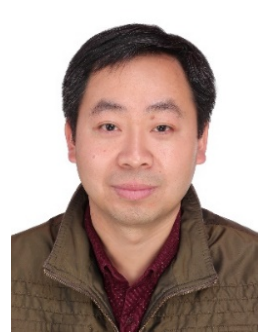

Chengqing YUAN. He received his M.S. degree in mechanical design and theory at Wuhan Research Institute of Materials Protection, China Academy of Machinery Science and Technology in 2001 and Ph.D. degree in vehicle operating engineering at Wuhan methyl cellulose grafted with polyacrylamide. Cellulose 19: 933-945 (2012)

[29] Ma S H, Scaraggi M, Wang D A, Wang X L, Liang Y M, Liu W M, Dini D, Zhou F. Nanoporous substrateinfiltrated hydrogels: A bioinspired regenerable surface for high load bearing and tunable friction. Adv Funct Mater 25: 7366-7374 (2015)

[30] Ganji F, Vasheghani F S, VasheghanI F E. Theoretical description of hydrogel swelling: A review. Iran Polym $J$ 19: 375-398 (2010)

[31] Ma L, Gaisinskaya-Kipnis A, Kampf N, Klein J. Origins of hydration lubrication. Nat Commun 6: 6060 (2015)

[32] Li Z X, Ma S H, Zhang G, Wang D A, Zhou F. Soft/hard-coupled amphiphilic polymer nanospheres for water lubrication. ACS Appl Mater \& Inter 10: 9178 9187 (2018)

been a Ph.D. student of the School of Energy and Power Engineering at Wuhan University of Technology since 2017. His research area is marine green tribology.

2006. She joined the School of Energy and Power Engineering at Wuhan University of Technology in 1997. Her current position is a professor and the head of the Department of Marine Mechanical Engineering. Her research areas cover marine tribology, ship antifouling \& drag reduction, and corrosion \& wear under marine environment.

University of Technology in 2005. He joined the School of Energy and Power Engineering at Wuhan University of Technology in 2005. His current position is a professor and the vice dean of the school. His research areas cover marine tribology, new energy aided ship power system, and ship energy efficiency improvement. 